\title{
Research on the Present Situation and Countermeasures of Logistics Development in Xiong'an New District
}

\author{
Shuguo Zhang', Qian $\mathbf{L i}^{2}$ \\ Department of Economic Management, North China Electric Power University, Hebei Province, \\ Baoding City, China
}

Keywords: Xiong'an New District, Sustainable Development, Logistics Development

\begin{abstract}
Xiong'an New District, as another nationally significant new district following the Shenzhen Special Economic Zone and the Pudong New Area, must not only undertake the non-capital function of Beijing, but also develop high-end high-tech industries. The development of the logistics industry needs further improvement. In order to boost the logistics industry development in Xiong'an New District, this paper analyzes the location, economic status, and logistics status of Xiong'an New District and proposes improvement strategies for the existing problems to provide support for the sustainable development of Xiong'an New District.
\end{abstract}

\section{Introduction}

On April 1, 2017, under the background of the coordinated development of Beijing, Tianjin, and Hebei, the central government proposed an important decision to build Xiong'an New District. As the new district following the Shanghai Pudong New Area and the Shenzhen Special Economic Zone, it will have the next strategic significance for the country's development. The Xiong'an New District is also the latest measure to implement the Beijing-Tianjin-Hebei co-development strategy following the planning and construction of Beijing's sub-center, and is therefore known as the "Millennium plan, national event." In the construction of the Xiong'an New District, the logistics service system is an important foundation for supporting sustainable development. However, currently, Xiong'an New District is mainly based on road traffic, and its transportation infrastructure is weak. It cannot meet the demand for future cargo transportation in Xiong'an New District. Therefore, it proposes solutions to the problems existing in logistics in Xiong'an New District to meet the logistics needs of Xiong'an New District, support the development of green traffic and assist the economic development of Xiong'an New District.

\section{Development background}

In May 2013, when General Secretary Xi Jinping investigated in Tianjin, he pointed out that the Beijing-Tianjin "Shuangchengji" should be written in the socialist modernization in the new period; in February 2014, when he visited Beijing and hosted a symposium, President Xi clearly proposed 
implementation of the Beijing-Tianjin-Hebei co-development strategy and the key strategy for coordinated development is to focus on resolving Beijing's non-capital-capital-related tasks. On April 2 and April 30, 2015, Xi Jinping presided over the CPC’s Central Government's politics. The Standing Committee meeting and the Political Bureau of the Central Committee studied the "Compendium of Beijing-Tianjin-Hebei Coordinated Development Plan" and emphasized once again that in order to conduct in-depth studies on the issue of the Metro, we can consider planning in a suitable place in Hebei Province and build a modern architecture led by new development concepts: Xincheng; On March 24, 2016, Xi Jinping presided over the meeting of the Standing Committee of the Political Bureau of the CPC Central Committee, and reviewed and agreed in principle with the "Report on the Administrative Sub-centers of Beijing Municipality and Relevant Information on Releasing Beijing's Non-Capital Functional Concentrated Bearing Areas" and determined the planning of the New District. The site selection agreed to be named "Xiong'an New District"; On May 27, 2016, the Political Bureau of the CPC Central Committee met in Zhongnanhai Rentang was convened to review the "Report on the Planning and Construction of the Beijing City Sub-center and Research on the Establishment of Hebei Xiong'an New District". The "Xiong'an New District" first appeared in the title of the report; On April 1, 2017, the Communist Party of China, the Central Government and the State Council issued a notice and decided to establish the Xiong'an New District in Hebei; In October 2017, the State Administration for Industry and Commerce published "Several Opinions on Supporting the Planning and Construction of Xiong'an New District in Hebei Province" on the official website, which proposed that the word "Xiong" be given special protection in the approval of enterprise names according to law, and "Hebei Xiong'an" was used as an administrative division.

After the establishment of Xiong'an New District, China Xiongan Construction Investment Group Co., Ltd., Xi'an Group's three wholly-owned subsidiaries China Xiongan Group Infrastructure Co., Ltd., China Xiong'an Group Investment Management Co., Ltd., China Xiong'an Group Public Service Management Co., Ltd. founded. In addition, the national power grid Xiong'an New District Power Supply Company is also listed and established. According to the Xiong'an New District power grid plan, it will achieve 100\% clean electricity, and be the first to become a $100 \%$ clean power supply of the urban power grid. The energy consumption accounts for $52 \%$ of the final energy consumption.

\section{Situation analysis}

\subsection{District Analysis}

Xiong'an New District is located in the hinterland of Beijing, Tianjin and Baoding. As shown in Figure 1, it is an equilateral triangle with Beijing and Tianjin. It is approximately 105 kilometers away from Beijing and Tianjin, 155 kilometers from Shijiazhuang and 30 kilometers from Baoding. Beijing's new airport is 55 kilometers with obvious advantages in location. 


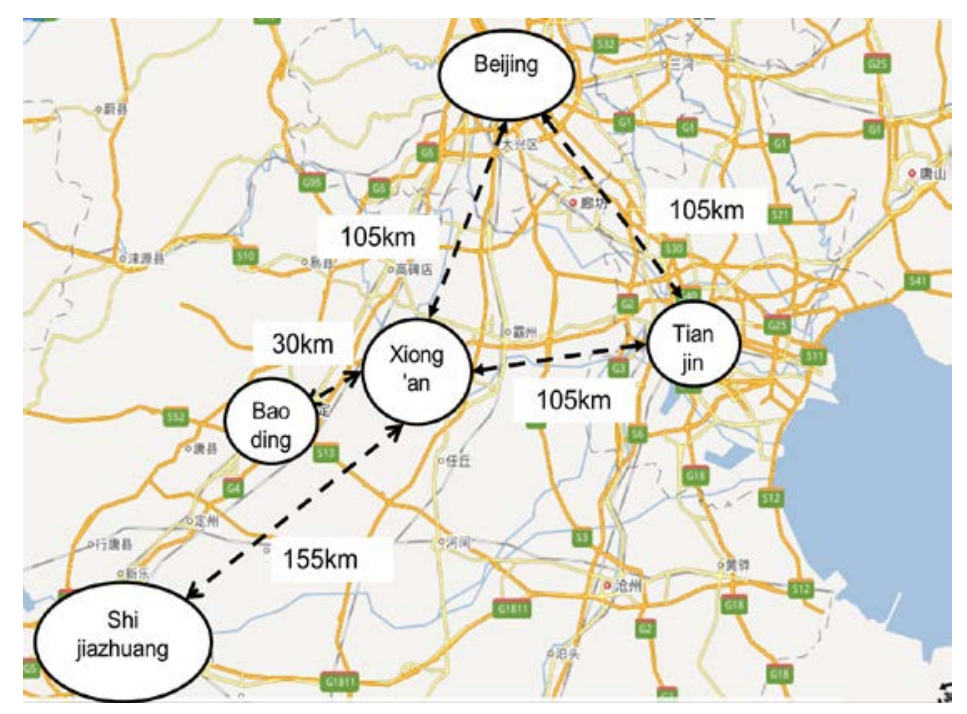

Figure 1 Location map of Xiong'an New District

Judging from the capital city location, Beijing's urban sub-center and Xiong'an New District are divided into the east and southwest sides of Beijing's central city as two wings, with clear positioning and dislocation development, and achieve new leaps; from Hebei's location, Xiong'an New District and the Zhangbei region, which will be promoted by the Beijing Winter Olympics as an opportunity by 2022, present a south and a north. It is also the two wings that drove the Yanzhao earth to take off.

In addition, Xiong'an New District will plan to form a "one main, five auxiliary, and multiple nodes" urban and rural spatial layout of the new district: "One main" is the starting area, and the junction area between Rongcheng and Anxin counties is selected as the starting area and is the master of the new district. In the urban area, construction is first started; "five auxiliary" main Xiong County, Rongcheng, Anxin County, and five peripheral groups of Zhaili and Fugang are fully upgraded to expand Xiong County and Rongcheng County, and Anxin County is optimized and adjusted. Construction of two groups, Zhaili and Shugang; "multiple nodes", that is, a number of characteristic small towns and beautiful villages, the development of classified features, the delineation of the development boundary of characteristic small cities and towns, and the prohibition of large-scale development of real estate.

Xiong'an New District is planned to be developed with a specific area as the starting area. The starting area is about 100 square kilometers, the medium-term development area is about 200 square kilometers, and the long-term control area is about 2,000 square kilometers.

\subsection{Economic Analysis}

According to the statistical content of Hebei Economic Yearbook-2017, the main indicators of the national economy of Xiong'an New District in 2016 are obtained: A1 to A4 respectively means GDP, The total retail sales of social consumer goods, total social investment in fixed assets and revenue from main business of industrial enterprises above designated size and unit is 100 million yuan. 
Table 1 Xiong'an New District Statistics in 2016

\begin{tabular}{|c|c|c|c|c|}
\hline Index & A1 & A2 & A3 & A4 \\
\hline Xiong contry & 101.14 & 53.54 & 76.73 & 222.63 \\
\hline $\begin{array}{c}\text { Rongcheng } \\
\text { country }\end{array}$ & 59.41 & 44.92 & 55.07 & 40.63 \\
\hline $\begin{array}{c}\text { Anxin } \\
\text { country }\end{array}$ & 57.88 & 49.62 & 77.85 & 105.94 \\
\hline
\end{tabular}

In Table 1, the regional GDP of Xiongan New Area, total retail sales of social consumer goods, investment in fixed assets of the entire society, and income from main operations of industrial enterprises above designated size accounted for $0.68 \%, 1.03 \%, 0.66 \%$, and $0.78 \%$ of Hebei Province respectively, accounting for a relatively low proportion. In addition, as of the end of June 2017, the permanent population of Xiong'an New District is 1,041,100 people, and the long-term planned population is 2 million to 2.5 million, and the population density is about 1,000 to 1,250 people per square kilometer.

In the new district, no matter whether a large number of central enterprises, headquarters enterprises enter, or research and innovation institutes or institutions of higher learning relocate, and administrative institutions and government affiliates enter the city, new consumer-oriented cities and even enjoyable-type consumer cities will still be formed. It is dominated by commerce and logistics. But with the existing resources and economic development, the development of the new area cannot be built without strong support from top-level policies, and it is even less likely to leave the reality market mechanism to achieve sustainable development. Beijing-Tianjin-Hebei Collaborative Logistics is also bound to respond to the short-term changes in the new logistics demand and supply space layout, and it must also respond to the requirements for sustainable development of the logistics industry that serves different economic needs with multiple levels, high efficiency, intelligence, and value creation.

\section{Analysis of Logistics Development Status}

In the aspect of highway traffic, Xiong County takes the expressway as the backbone and the county as the center. It possesses the four verticals (Daguang-Expressway, Jingangao Expressway, Lixin Road, Guxiong Line)and five horizons(Baojin Expressway, Line 112, Jinbao North Line, Baojing Road, and Baibai Road) to communicate the urban and rural road network; Rongcheng County's main traffic lines include the north line of Jinbao Highway (provincial 112 National Road), and Rongxiong Road, Ronggu Road and Rongan County. Highways of the highways and Rong-Jia highways totaling $56 \mathrm{~km}$; Traffic trunk lines in Anxin County include Jing-Kun Expressway, National Highway 107, Beijing-Hong Kong-Macao Highway, Bao-Zu Freeway, Bin-Bao Expressway, Bao-Bao Expressway, Zhang The Shijiazhuang Expressway is also connected by the Beijing-Hong Kong-Macao Highway, the Rongwu Expressway, the Beijing-Kunming Expressway, and the Bao-Bao-Bao Expressway around Anxin County to form a high-speed outer ring. In terms of railway transportation, there are no railway lines and cargo yards within the three counties, Beijing-Guangzhou Railway Line (Beijing West-Guangzhou), Beijing-Kowloon Railway Line (Beijing West-Kowloon), and Tianjin Railway Passenger Trainer (Tianjin West-Baoding) three railway lines radiate three counties, and freight yards approaching three counties are Gaobeidian station freight yard, Xushui station freight yard, and Wuzhou station freight yard respectively.Among them, the Gaobeidian station freight yard is located on the west side of the Beijing-Guangzhou line, and the center mileage is located at $73 \mathrm{~km}+131 \mathrm{~m}$ of the BeijingGuangzhou line; the Xushui station freight yard is located on the east side of the Beijing- 
Guangzhou line, and the center mileage is located at $110 \mathrm{~km}+901 \mathrm{~m}$ of the Beijing-Guangzhou line; The state station cargo yard is located on the east side of the Beijing-Guangzhou line, and its center mileage is located at $52 \mathrm{~km}+800 \mathrm{~m}$ of the Beijing-Guangzhou line. According to the analysis of past transportation, the transportation network can support the existing logistics and transportation. However, in the "Beijing-Tianjin-Hebei Trade and Logistics Coordinated Development Plan," it also puts forward new requirements for the logistics level of Xiong'an New District. Therefore, the logistics of the new district The actual effectiveness needs to be developed. At present, the efficiency of information technology in the region is relatively poor, which has a greater binding force on the development of intelligent logistics industry and is not conducive to the long-term stable development of the logistics industry. However, from the analysis of the traffic capacity of the area, its ability to connect with other regions is stronger, which provides favorable geographical advantages for logistics transshipment. Therefore, it can prove that the region has strong development space for logistics industry.

\section{Existing development plan}

Xiong'an New District plans to build six railways, four high-speed rail stations, and one airport, and plans to build it in the next three years.

In terms of railways, the Jinbao Railway that had been opened in the Xiong'an area since the end of 2015 and had two stations at Baigou Station and Baiyangdian Station. They are existing sites within the planning area of the Xiong'an New District. In the future, plans will be made for the addition of Xi'an Railway Station and Xiong'an East Station two high-speed rail stations. According to the Xiong'an high-speed rail plan, there are a total of five railways passing through the Xiong'an area. Two of the Beijing-Xiongg railway and the Jinxiong railway will reach Beijing and Tianjin from Xiong'an. Line of Beijing-Xiong Country has a total length of 92.783 kilometers. There are five stations across the railway, namely Huangcun Station, New Airport Station, Gu'an Station, Bazhou North Station, and Xi'an Railway Station. The line will be completed in February 2020. The total construction period is two years. After the completion of the line, Xiong'an Station will become the road network main and passenger station of Xiong'an New District, and the integrated transportation hub on the ground. It will mainly serve mid- and long-distance passenger traffic in the new area, and will be closely linked with the national high-speed rail network. Among them, the design speed of Liying to New Airport section in Beijing is $250 \mathrm{~km} / \mathrm{h}$, among which, BeijingXiongung intercity is all in the Daxing district of Beijing. From the new airport to the new section of Xiong'an, the design speed is about $350 \mathrm{~km} / \mathrm{h}$. The total investment is about 33.377 billion yuan. There are two stations in Huangcun Station and New Airport Station in Beijing, and the route has maintained the original Beijing Bacheng inter-city plan. This section of the project has already started construction.

Aviation: In 2017, Xiong'an General Airport was opened and it is planned to be completed in 2019.

\subsection{Analysis of problems}

Xiong'an New District has a higher development positioning than Shanghai Pudong New Area and Shenzhen Special Economic Zone. However, from the analysis of its basic conditions for development, the economic foundation of Xiong'an New District is relatively weak and the two are far apart. Through its analysis, Huatai Securities predicts that Xi'an New District will have a total capital investment of more than RMB 600 billion in 15 years. The goal of slowing down non-capital functions in Beijing for logistics system construction is particularly prominent. Therefore, a new positioning has also been proposed for the main functions of the logistics system in Xiong'an New 
District. To expand the service function of the Xiong'an New District logistics system, it is imperative to increase the total logistics freight volume in Xiong County, Anxin and Rongcheng counties.

In addition, although the development of logistics industry in Xiong'an New District is relatively complete, there are only 52 logistics and distribution companies in the three counties, and there are fewer than 1,000 distribution vehicles that can operate around the clock. There are 126 trunk logistics companies and less than 3,000 operational vehicles. There are many small and mediumsized enterprises in the three counties, including women's shoes, home wear, 3C digital accessories, specialty snacks, toiletries, children's diapers, and household daily use. Although Xiong'an New District's total shipments in 2016 exceeded 26,000 tons, the actual transport volume is still at a low level of transportation. The basic reason is that the logistics system in the three counties has not yet been perfected, and a relatively poor market competition has formed. Moreover, the quality of most logistics companies is relatively low, and the level of production organization and management methods are relatively backward. In particular, the lack of information management means that the actual logistics efficiency is not high. However, from the analysis of the total shipments of the three stations in Zhangzhou, Xushui and Gaobeidian, there is still much room for development in the region. Relevant survey data showed that between July 2016 and July 2017, 158,600,000 tons of military supplies were shipped within the jurisdiction of the three counties, 12.58 million tons of chemical fertilizers were shipped, and 6.7 million tons were shipped. According to relevant data from the survey data of big data rookie surveys, Xiong County's rural single-quantity logistics and freight transportation ranks first in the country, of which the amount of e-commerce transactions accounted for $79.58 \%$ of the total. From the overall industry situation analysis, the existing logistics system is not enough to consume the ever-expanding production volume. Especially under the realistic demand of the total design of the Xiong'an New District, it is particularly important to continue to expand the logistics system and its market coverage and improve the construction of its information system.

\section{Development strategy}

China plans to build Xiong'an New District to highlight the construction of a green, smart new city, build a world-class, green, modern, smart city; provide quality public services, build quality public facilities and create a new model of urban management; build a fast and efficient transportation network, build a green transportation system Therefore, the following development strategies are proposed in response to the above issues:

\subsection{To Build a Modern Integrated Logistics Center}

It is necessary to build a fast and efficient transportation network in accordance with the Xiong'an New District, to create an overall deployment of the green transportation system, and to build a specialized modern international logistics center so as to cooperate with Xiong'an Regional economic development in the New District, adjustment of industrial structure, and requirements for transformation and upgrading of relocated enterprises.

\subsection{Improve Short-Distance Distribution Capacity}

According to the needs of building a green, smart new city in Xiong'an New District, building a world-class, green, modern, and smart city planning requirement, it is necessary to purchase energysaving and environmentally-friendly electric vehicles, integrate existing railroad internal pick-up service delivery vehicles, and related Personnel and information systems, strengthen cooperation 
with social logistics companies, improve the current situation of insufficient short-distance railway distribution capacity, establish an "Internet +" urban intelligent distribution system to realize intelligent operation of urban distribution in Xiong'an New District, and improve the distribution efficiency and service level of the new district. The use of big data analysis to rationally allocate distribution outlets, overall equipment and facilities, and personnel arrangements is to reduce urban congestion, and establish an efficient and intelligent low-carbon logistics chain end distribution system.

\subsection{Expand 020 Logistics Operation Function}

As the network layout of Xiong'an New District is not perfect during the initial stage of construction, if the 020 model is adopted to expand the scope of logistics transportation, whether it will reduce the safety factor of the cargo is also a realistic issue that needs repeated consideration. If we can improve the infrastructure construction of intelligent road port logistics as soon as possible, we can support the actual demand for the operation of the 020 logistics model. However, in the absence of corresponding sites and initial network construction, it is necessary to expand the service function of the 020 logistics model, and to improve the product safety of logistics transportation with the fine degree of management of product quality, cost, effectiveness, and resources. If you adopt the 020 linkage model of multiple commercial entities, you need to further strengthen the specific functions of after-sales services and product delivery and implementation, and you need to increase the technical control of the transportation, acceptance, collection and distribution of goods, and receipt of information, and then realize The logistics production process is refined to improve the actual safety of cargo transportation. In the mid-development phase of the new zone, after the corresponding infrastructure is completed, for the realization of sustainable development, it is also necessary to further improve resource matching, transportation mode selection, line selection, resource operation, and timely updating of related product information, thereby improving storage systems, order systems, the practical functions of transportation systems, vehicle dispatch systems, mobile terminal systems, automatic sorting systems, and customer service systems are designed to support the integration of logistic network operations and function development.

\section{Results and conclusions}

To sum up, according to the analysis of Xiong'an New District, it is possible to find its geographical characteristics of developed transportation and geographical coverage, and it has a relatively high development base and space for the construction of the economy and logistics industry, but also tests the service capacity and operating efficiency of logistics industry at the same time. In the core development concept of the "Millennium plan and national events" in the Xiong'an New District, building a logistics industry system with high service efficiency is an objective requirement for the development of the New District. Therefore, in the main function of

the logistics system of Xiong'an New District, it must be able to relieve the non-capital function of Beijing. However, the infrastructure construction of the logistics system does not happen overnight. It requires a certain construction time and break-in period. Modern integrated logistics centers, improved short-distance distribution capabilities, and expanded 020 logistics operations aim at improving the logistics system, supporting the macro goals of Xiong'an New District construction, and promoting the implementation of the strategic plan for the sustainable development of Xiong'an New District. 


\section{References}

[1] Liu Dacheng. Leading the master planning of Xiong'an New District with Beijing-Tianjin-Hebei special logistics planning[N]. Economic Information Daily, 2017-04-11(006).

[2] Sun Bindong. From Tongzhou to Xi'an: The Practice and Practical Significance of China's Multi-Centric Space Strategy [J]. National Governance, 2017, (18): 17 - 23.

[3] Editorial Office of the Journal, Xiao Jincheng, Guo Kesha, Lu Jun, Liu Bingjun, Li Lanbing, Yin Cunyi, Tian Xuebin, Zhang Gui, Zhou Mi, Sun Zhexi The choice of strategic development in Anxin District "Xiong'an New District and Beijing-Tianjin-Hebei Collaborative Development: Theory and Policy, "Excerpts from the Speeches of Experts on High-end Forum (Top) Tian Economy and Management, 2017, 31 (03) : 6-12. (2017-05-10).

[4] Liang Benfan's strategy to seize Xi'an to build new opportunities and accelerate the development of Tianjin Binhai New Area. Tiancheng, 2017, (05): 3-7.

[5] Ji Lianggang, Tian Xuebin, and Zhao Peihong lead the development of Xiong'an New District with innovative reform and opening up [J]. Financial Intelligence, 2017, 2 (03): 24-36+138-139.

[6] Summarization of the "Beijing-Tianjin-Hebei Financial Cooperative Development Forum 2017" Conference. The DTR Research Institute's Field Financial Theory Exploration, 2017, (03): 79-82.

[7] Meng Guangwen, Jin Fengjun, Li Guoping, Zeng Gangxiong, Anxin District: Opportunities and Challenges in Geography[J]. Geographic Research, 2017, 36 (06): 1003 -1013. (2017-06-23). 